\title{
Justice for Millionaires?
}

\author{
David Axelsen (Essex), \\ James Christensen (Essex), \\ Tom Parr (Warwick)
}

\begin{abstract}
In recent years, much public attention has been devoted to the existence of pay discrepancies between men and women at the upper end of the income scale. For example, there has been considerable discussion of the "Hollywood gender pay gap". We can refer to such discrepancies as cases of millionaire inequality. These cases generate conflicting intuitions. On the one hand, the unequal remuneration involved looks like a troubling case of gender injustice. On the other, it's natural to feel uneasy when confronted with the suggestion that multi-millionaires are somehow being paid inadequately. In this paper, we consider two arguments for rectifying millionaire inequality, clarifying their appeal but also identifying the obstacles that each will have to surmount in order to succeed.
\end{abstract}




\section{Introduction}

In July 2017, the BBC published a list detailing the salaries of its top earners, which revealed a significant gender pay gap among its presenters. Only a third of those on the list were women, and there were substantial pay differences between men and women who were similarly placed in the corporation. For example, despite both joining the BBC in the 1980s, and despite both being lead presenters on similar programmes, Huw Edwards's salary was revealed to be approximately $£ 200,000$ higher than that of Fiona Bruce (Grierson 2017). Pay inequality of this kind is not unique to the UK, nor is it unique to the television industry. The Hollywood actor, Jennifer Lawrence, and the tennis star, Serena Williams, have each been involved in highly publicised pay disputes. Both have argued that they are paid less than their male counterparts because they are female (Lawrence 2015; Williams 2017). ${ }^{1}$ These are cases of millionaire inequality. ${ }^{2}$

When such cases are discussed in the media, they are standardly followed by a call to action. In a letter addressed to Tony Hall, the Director-General of the BBC, Fiona Bruce and her fellow female top earners write: 'You have said that you will 'sort' the gender pay gap by 2020, but the BBC has known about the pay disparity for years. We

\footnotetext{
${ }^{1}$ As there are no commonly used adjectives to denote gender in English, we use 'male' and 'female' to refer to men and women.

${ }^{2}$ Of course, in quotidian usage, any disparity in earnings among millionaires constitutes a millionaire inequality, but in this paper we use the phrase to refer exclusively to cases where female millionaires are paid less than their male counterparts, apparently on the basis of their gender.
} 
all want to go on the record to call upon you to act now' (The Telegraph 2017). Similarly, on Black Women's Equal Pay Day, Serena Williams authored an essay stating that: 'We need to push this issue to the front of conversations so that employers across the U.S. can truly understand that all male and female employees must be compensated equally. Not close. Not almost the same. Equally' (2017).

Cases of millionaire inequality generate conflicting intuitions. On the one hand, the unequal remuneration involved looks like a troubling case of gender injustice. These inequalities constitute one further example of the multiple ways in which our ostensibly liberal societies subordinate women's interests to those of men. On the other hand, it's natural to feel uneasy when confronted with the suggestion that multimillionaires are somehow being paid inadequately. Indeed, this sense of unease is registered by some of the most outspoken critics of millionaire inequality. In an essay addressing the issue, Lawrence writes: 'It's hard for me to speak about my experience as a working woman because I can safely say my problems aren't exactly relatable.' After suggesting that she had refrained from negotiating for higher pay, Lawrence notes: 'I didn't want to keep fighting over millions of dollars that, frankly ... I don't need' (2015).

Indeed, it might be suggested that the attention devoted to these inequalities vindicates various misgivings recently expressed by some radical feminists. Condemnation of the 'Hollywood pay gap' prompts one to recall Nancy Fraser's lament that 'feminist ideas that once formed part of a radical worldview are increasingly expressed in individualist terms' (2013). Elaborating on the nature of her concern, Fraser comments: 'Where feminists once criticised a society that promoted careerism, they now advise women to 'lean in'. A movement that once prioritised social solidarity now celebrates female entrepreneurs' (2013). 
In this respect, the campaign against millionaire inequality differs markedly from the concurrent \#metoo campaign, which exposed the disturbing extent of sexual assault and harassment against women. Whereas the former can elicit ambivalence, the latter often attracts unreserved support. This is surely because, while we are confident in our judgements about the wrongness of sexual assault, establishing the wrongness of millionaire inequality is considerably more difficult. ${ }^{3}$

How, then, might one make the case for rectifying millionaire inequality? In this paper we identify and evaluate two distinct arguments. ${ }^{4}$ They are as follows:

1. The Fairness Argument: We should rectify millionaire inequalities because they are unfair, and they are unfair because they are attributable to differences in gender, which are morally arbitrary.

\footnotetext{
${ }^{3}$ We do not deny that, in practice, the two phenomena are rooted in the same soil, namely, the occupation by men of many or most of society's positions of power. But for the purpose of this paper, we focus on the analytically distinct questions surrounding millionaire inequalities.

${ }^{4}$ We recognise that these are not the only ways in which to justify rectifying millionaire inequality. For example, we might think that tackling millionaire inequality is important not because doing so benefits millionaires, but because it serves the interests of women who are considerably less advantaged. Fiona Bruce and other female high earners suggest this line of reasoning in their letter to the Director-General of the BBC, emphasising that ' $[\mathrm{t}] \mathrm{his}$ is an opportunity for those of us with strong and loud voices to use them on behalf of all'. See The Telegraph (2017). Perhaps the most serious problem with this view is that, if what motivates the argument is a concern for the plight of low income women, it's natural to wonder why, instead of supporting the campaign against millionaire inequality, we should not opt instead to support policies aimed specifically at removing the injustices that these women face. For some additional reasons to be sceptical of this argument, see Gheaus (forthcoming).
} 
2. The Discrimination Argument: We should rectify millionaire inequalities because the victims are subjects of wrongful discrimination.

We address these arguments in turn, clarifying their appeal but also identifying the obstacles that defenders of each will have to surmount in order to succeed. We register our support for (a particular version of) the second, discrimination-based, argument, while casting doubt on the efficacy of the first. In our conclusion, we explore the distinctiveness of cases of millionaire inequality by reflecting on the extent to which our conclusions generalise beyond society's very highest earners.

Before we begin, there are three prefatory points to be made. First, the statements of the three arguments above claim that 'we' should rectify millionaire inequalities. This formulation is used as shorthand for the claim that one should support calls to rectify millionaire inequality because there are compelling moral reasons to do so. If there really are compelling moral reasons to rectify millionaire inequality, a further question asks who should do the rectifying. In particular, should the rectification be enforced by the state? We shall take no stance on this question.

Second, we take millionaire inequality to be an example of a broader phenomenon, namely, putatively morally problematic pay inequalities among the relatively wellendowed. Thus, while we focus throughout specifically on the case of gender-based inequalities, the arguments we develop may shed similar light on related trends, such as Hollywood's race pay gap. Our reason for limiting our investigation to the gender pay gap in particular is only because doing so enables us to focus and direct sustained philosophical attention towards an interesting, distinctive, and politically salient set of questions that warrant closer scrutiny. 
Third, we acknowledge that we are not the first to consider cases of this kind. In particular, our analysis contributes to a debate recently triggered by Anca Gheaus's treatment of related topics (forthcoming; unpublished manuscript). Our intention is to complement Gheaus's analysis by further exploring the intricacies of these issues, as well as the relevance of a variety of additional factors that don't arise in her discussion of these matters.

\section{The Fairness Argument}

\subsection{Introducing the Fairness Argument}

The Fairness Argument holds that millionaire inequalities are morally objectionable because they are unfair, and that we should rectify such inequalities because of this unfairness. This argument draws on the idea that it's unfair for some individuals to receive less favourable remuneration than others simply in virtue of factors that are morally arbitrary. Female millionaires who are paid less generously than their male counterparts simply because they are women are disadvantaged by a morally arbitrary factor, their gender, and are therefore treated unfairly.

We can characterise morally arbitrary factors in one of two related but distinct ways. We can take a factor to be morally arbitrary (i) if it fails to track individual choice and responsibility, or (ii) if it fails to track any consideration that we could plausibly regard as a determinant of one's entitlements. ${ }^{5}$ When it comes to explicating the unfairness of

\footnotetext{
${ }^{5}$ Those who characterise morally arbitrary factors as those that fail to track individual choice also often believe that individual choice is the one consideration that ought to affect one's life prospects (though they need not think that one should always have to bear the consequences that happen to attach to a particular choice under particular circumstances). Those who characterise morally arbitrary factors as those that fail to track any considerations that should affect one's life prospects might accept that certain
} 
granting less favourable treatment to members of a particular gender, the second notion of moral arbitrariness seems more appropriate than the first. To see why, imagine a science-fiction scenario in which we are able to choose our gender freely before entering society. There may be good reasons why one might choose to be a woman even if one knows that society is structured in a manner that burdens women with socioeconomic disadvantages. But one's choice to be a woman does not deprive one of justice-based resources with which to criticise the inegalitarian nature of one's society. It remains the case that there is no good reason why socio-economic disadvantages should attach to that choice. One's gender remains morally arbitrary in the second sense distinguished above.

As a property that is morally arbitrary in this sense, one's gender contrasts with a number of other considerations that might plausibly be regarded as relevant to a moral assessment of distributive outcomes. It's prima facie plausible that someone who performs a job that is especially socially valuable or arduous should enjoy higher pay than someone who occupies a less valuable or burdensome position. But it's not at all plausible that someone should enjoy higher or lower pay than others simply in virtue of their gender.

The Fairness Argument is intuitively attractive. However, in the next subsection we demonstrate that it's defeated by what we shall call the Excess Objection. But before proceeding, let's note that there are two ways in which millionaire inequalities could be rectified. These can be described using Jennifer Lawrence as our example of a female

factors not attributable to choice (such as the distribution of natural talent) can justly influence people's prospects, and therefore count as non-arbitrary. On the different conceptions of moral arbitrariness present in the literature, see Caney (2009: 396-397). 
victim of millionaire inequality and Christian Bale as our example of a male beneficiary of millionaire inequality. The first rectificatory strategy is to raise Lawrence's pay to the level of Bale's; the second rectificatory strategy is to lower Bale's pay to the level of Lawrence's. ${ }^{6}$ We develop the Excess Objection with the first rectificatory strategy in mind, but, at the end of the subsection, we show how it also impugns the second as well.

\subsection{The Excess Objection}

According to the Excess Objection, female millionaires, like their male counterparts, already have more than their just share of resources, and we cannot plausibly maintain that they have a fairness-based claim to even more. The details of this objection, which we endorse, are as follows. ${ }^{7}$ In a just society, the excess wealth of the super-rich would be taxed away. The higher rewards for female millionaires recommended by the first rectificatory strategy would, if paid, be immediately expropriated by the state. Moreover, in the absence of just tax-and-transfer arrangements, the super-rich have a moral obligation to relinquish their fortunes voluntarily (e.g. by donating them to charity). The most compelling theories of distributive justice yield the conclusion that the excess wealth of the super-rich should be regarded as morally analogous to stolen

\footnotetext{
${ }^{6}$ A third rectificatory strategy is to raise Lawrence's pay to some point between her current pay and Bale's current pay, and lower Bale's to the same level. As this strategy raises no distinctive normative issues, we set it aside.

${ }^{7}$ For a similar defence of this objection, see Gheaus (forthcoming). Our analysis goes beyond Gheaus's in that we distinguish different versions of this objection, corresponding to three distinct ways in fairness might interact with the needs of the world's poor. We elaborate on this below.
} 
loot. The fact that the loot in question is distributed unequally does not provide those who receive less with a fairness-based claim to more.

A variety of familiar reasons support the claim that inordinately large accumulations of wealth among individuals have no place in a just society. ${ }^{8}$ Some egalitarians argue that it's simply unfair for some people to have so much more than others, given that brute luck inevitably plays a prominent role in determining who gets what. Others explain the injustice of large inequalities by pointing to the pernicious effects that they engender. These egalitarians argue that large economic inequalities often translate into inequalities of power, and that the better-off are often able to dominate or control the lives of the less advantaged in objectionable ways (Schemmel 2011). Furthermore, large disparities of wealth can undermine the fairness of certain political procedures, and impede the creation of genuinely equal opportunities in education and the labour market (Christiano 2012).

But perhaps the most powerful and straightforward objection to large inequalities is that they represent a failed opportunity to rectify severe disadvantage. This objection, which can be effectively mobilised to serve our ends, focuses on absolute deprivation, and makes no reference to the idea that it's necessarily bad for some to fare worse than others in merely comparative terms. ${ }^{9}$ As T. M. Scanlon writes:

In some cases our reason for favoring the elimination of inequalities is at base a humanitarian concern - a concern, for example, to alleviate suffering. If some people are living under terrible conditions, while others are very well off indeed,

\footnotetext{
${ }^{8}$ For a helpful taxonomy of arguments against inequality, see Scanlon (2002). See also Robeyns (2017).

${ }^{9}$ What we are concerned with is 'the hunger of the hungry, the need of the needy, the suffering of the ill, and so on' (Raz 1986: 240).
} 
then a transfer of resources from the better to the worse off, if it can be accomplished without other bad effects, is desirable as a way of alleviating suffering without creating new hardships of comparable severity (2002: 42).

It's no secret that in our world there are not merely 'some', but a great many people living under terrible conditions. More than 700 million people survive each day on less than what could be purchased in the United States for $\$ 1.90$ (Human Development Report 2016: 29). Each year, almost 6 million children die before reaching the age of five, and nearly half of these children lose their lives because they do not have enough food (Human Development Report 2016: 30; Hug, Sharrow, and You 2017: 3). Moreover, those involved in movements like 'Effective Altruism' have drawn our attention to the fact that these kinds of deprivations can be ameliorated at little cost. For example, Peter Singer points out that a donation of $\$ 250$ could provide rehydration therapy to a child who would otherwise die from diarrhoea (Singer 2009: 88-89).

It's these well-known facts about the extreme poverty that disfigures our world, and about the ease with which it can be mitigated, that make the extravagant fortunes of the super-rich so instinctively repellent. It's also such facts that provide the strongest support for our claim that these fortunes should be seen as analogous to stolen loot. Given the crushing burdens endured by the world's poorest people, the super-wealthy can have no just claim to the enormous wealth that they have amassed. Like thieves in possession of stolen goods, the rich must relinquish their holdings.

But how, exactly, does the Excess Objection defeat the Fairness Argument? This depends on how we conceive of fairness as a value and on how considerations of fairness interact with the needs of the world's poor. The Excess Objection might defeat the Fairness Argument in three possible ways, which we can again describe using 
Lawrence and Bale as our respective examples of victims and beneficiaries of millionaire inequality.

First, we might concede that Lawrence does suffer some morally problematic unfairness. After all, Lawrence is paid less than Bale, and, assuming her lower pay is attributable to her gender, which is morally arbitrary, this inequality in remuneration is certainly unfair. However, because Lawrence (like Bale) already has so much more than most, and can contribute to ameliorating the desperate plight of the world's poor at such little cost to herself, she is morally required to tolerate this unfairness all-thingsconsidered. Indeed, she is morally required to donate much of the wealth that she already possesses to charity. Raising Lawrence's pay would enlarge that portion of her holdings that she is morally required to relinquish. On this account of how the Excess Objection defeats the Fairness Argument, each raises distinct moral concerns (of fairness and, say, basic need fulfilment), and Lawrence's interest in fairness is outweighed by the basic needs of the world's poor. On this view, fairness is one value to be weighed against others.

The second account is closely related. Again, we begin by conceding that Lawrence suffers some morally problematic unfairness. But we then point out that the severe burdens borne by the world's poorest individuals, and the radical inequality between these individuals and people like Lawrence, are themselves a product of unfairness. Lawrence has been spared various misfortunes - such as being born into an impoverished country - that have devastated the lives of millions, while being blessed with various advantages, arbitrary from the point of view of morality, that enable her to lead an extraordinarily privileged life. On this account, Lawrence's interest in fairness conflicts with the interest that the world's poor have in fairness. And, because the unfairness suffered by the latter is so much greater than the unfairness suffered by 
Lawrence, and exposes its victims to such catastrophic disadvantages, it's the claims of the world's poor that win out. Here, the Excess Objection and the Fairness Argument raise similar (fairness-related) moral concerns of different gravity. And, once again, Lawrence's interest in fairness is outweighed.

The third account of how the Excess Objection defeats the Fairness Argument is more distinctive. The general idea at the heart of the Fairness Argument is that unfairness obtains when some individuals receive fewer goods than others simply in virtue of factors that are morally arbitrary. This is a plausible claim. But it's also plausible to hold that the value of fairness is conditional. Sometimes, the fact that a particular distribution of goods is fairer than others provides no reason at all to favour that distribution. ${ }^{10}$ More specifically, the fact that a particular distribution of goods is fairer than others provides no reason to favour that distribution when the goods in question are not justly held. The Excess Objection reveals that the wealth of millionaires like Lawrence and Bale is not justly held; these millionaires are morally required to relinquish their holdings. Unlike the two previously stated accounts, the present account identifies no morally problematic unfairness in the unequal pay between the two actors. Therefore, while increasing Lawrence's pay to the level of Bale's may succeed in rectifying some unfairness, this fact provides no reason to increase Lawrence's pay. Because of this, there is no morally relevant unfairness to weigh against the claims of the world's poor. We can characterise this point by saying that the fairness achieved by

\footnotetext{
${ }^{10}$ We might say that fairness is an 'occasional value'. See Estlund (2008: 68).
} 
rectifying millionaire inequality has no intrinsic value. ${ }^{11}$ We can call this the No Intrinsic Value Claim.

While the first two accounts of how the Excess Objection defeats the Fairness Argument hold that the unfairness suffered by Lawrence is outweighed - either by a concern for the basic needs of the world's poor or by their interest in fairness - the third account that we have just sketched denies that the unfairness suffered by Lawrence constitutes any value that we should place on the scales. It premises this denial on what we can call the Just Holdings Condition, according to which improving the fairness of a distribution is intrinsically valuable only when the distribuenda are justly held. To see whether this condition is plausible, let's consider two scenarios: ${ }^{12}$

Slaves: The government of a slave state distributes slaves on a random basis to its citizens. Consequently, some citizens end up owning more slaves than others. Responding to complaints of unfairness, the government reallocates the slaves, ensuring that they are distributed equally among the citizenry.

Pizza: A pizza ordered by their housemate is received by Arthur and Brenda, who decide to keep it for themselves. Brenda proposes a 2:1 division, but when Arthur complains that this is unfair, Brenda agrees to divide the pizza equally.

\footnotetext{
11 This way of conceiving of fairness - as only conditionally valuable - coheres with a natural understanding of various other virtues. For example, bravery lacks value when exhibited in the pursuit of unjust ends. Similarly, loyalty is not valuable when shown to malevolent individuals.

${ }^{12}$ The cases are modified from Gheaus (forthcoming).
} 
We imagine that most readers will share our intuitive judgement that, even if the government reallocation in Slaves is conducive to fairness, this fact provides no reason to favour the reallocation. Fairness has no intrinsic value here and, as Gheaus plausibly notes, one natural explanation of this result is that the distribuenda in question (slaves) are not justly held: 'the reform cannot cater to any individual's claim of justice: Nobody should hold slaves, hence nobody has a claim to an opportunity to hold slaves' (forthcoming).

Our judgement regarding Pizza is analogous. The fairness of the equal division has no intrinsic value given that the pizza is not rightfully theirs. However, we recognize that some readers may demur from our analysis of Pizza, believing that a fair distribution of the stolen pizza has some intrinsic value. Some readers might hold that, if an equal division really is fairer than Brenda's original proposal, then that fact provides a reason to favour the former in this case. Those who are willing to countenance this view must abandon the Just Holdings Condition. Moreover, those readers who do not want to jettison the belief that we have no fairness-based reason to favour the reallocation in Slaves must provide an explanation of our conflicting judgements in the two cases.

One candidate-explanation is as follows. While it's possible to own a pizza permissibly, it's not possible to own a slave permissibly: owning slaves is always unjust, whereas owning a pizza is not. Because owning slaves is never permissible, distributing slaves fairly cannot be a virtue. By contrast, because it's possible to own pizza permissibly, improving the fairness of a distribution of pizza can be a virtue, even when the pizza is unjustly held.

If this is an adequate explanation of why a fair distribution of unjustly held goods can be an intrinsic virtue under some circumstances but not under others, then we should 
concede that there are reasons of fairness to rectify millionaire inequalities, since money (like pizza but unlike slaves) can be held justly. However, we do not find this explanation appealing. While we can certainly distinguish between things that can and cannot be permissibly held, employing this distinction to justify the rectification of millionaire inequalities is puzzling. The fact that a particular good can be justly held might help to establish why ensuring a fair distribution of that good can be intrinsically valuable. But it does not help to establish that a fair distribution of that good can be intrinsically valuable even when the good is not justly held. In the absence of a compelling reason to believe that the fairness of a distribution of unjustly held goods is a virtue, we should reject the current explanation.

An alternative explanation of why a fair distribution of unjustly held goods can be intrinsically valuable under some circumstances but not under others refers to the degree of injustice that individuals suffer in being deprived of their just holdings (Gheaus forthcoming). When some people own slaves, others suffer massive deprivations. By contrast, the retention of stolen pizza translates into a trifling burden for the rightful owner. Because slaves are deprived of their most basic entitlements, a fair distribution of slaves cannot be intrinsically valuable. The fairness is robbed of its value by the gravity of the injustice involved. By contrast, we might think that, because the wrongness of retaining stolen pizza is so minor, the intrinsic value of a fair distribution is not extinguished.

Supposing that this is a plausible explanation, the relevant question for present purposes is as follows: does the unfairness of millionaire inequality have more in common with an unfair distribution of slaves or with an unfair distribution of stolen pizza? For reasons that should by now be apparent, our view is that it has more in common with the former (though we do not suggest that being rich is as bad as being a slave owner). 
The hoarding of excess wealth by the super-rich constitutes the withholding of resources that could otherwise be used to ameliorate the desperate plight of the world's poor, and the super-rich are morally obligated to donate this wealth to effective poverty-relief organisations. ${ }^{13}$ It's because the hoarding of excess wealth translates into massive deprivations for others, and because the costs of avoiding this outcome are so small, that millionaire inequality cases have more in common with Slaves than Pizza. In virtue of these features, measures to rectify millionaire inequality are strong candidates for fairness-promoting actions that lack intrinsic value.

It's worth emphasising at this point that, in our view, the Just Holdings Condition is correct: improving the fairness of a distribution is intrinsically valuable only when the distribuenda are justly held, and the degree of injustice involved when the distribuenda are not justly held is immaterial. We went in search of an alternative defence of the No Intrinsic Value Claim only because we acknowledge that some readers may be reluctant to accept some implications of the Just Holdings Condition. By demonstrating that we can vindicate the No Intrinsic Value Claim even if we reject the Just Holdings Condition, we hope to have strengthened our position.

The implications of our view may be radical, but they are not as nihilistic as one might initially suspect. This is because, though the number of people who have more than their just share may be high, so too is the number of people who have less than their

\footnotetext{
${ }^{13}$ These two points can come apart. My retention of my left kidney constitutes the withholding of a resource that could otherwise be used to ameliorate the desperate plight of someone with end-stage chronic kidney disease, but still I might not be morally required to donate my left kidney. It's because the super-rich can donate their excess wealth at such trifling cost to themselves that they are morally required to do so.
} 
just share, and our view does not imply that fairness cannot have intrinsic value among this latter group of people. Suppose that a development agency is distributing medicine among the inhabitants of an impoverished village but, due to under-funding, it does not have enough medicine to go around. Assuming that everyone in the village has a just claim to the medicine, it follows that injustice will inevitably obtain. But it does not follow that, by seeking to distribute the medicine in a fair manner, the agency does nothing of intrinsic value. If distributive fairness requires that all those who have a just claim to the medicine have an equal chance of receiving it, say, then we should acknowledge that satisfying this standard is intrinsically valuable. ${ }^{14}$ Thus, even when justice is unachievable, ensuring a fair distribution can still be a virtue.

In developing the Excess Objection, we have had the Fairness Argument's first rectificatory strategy in mind. That is, we have focused on the claim that we should increase Lawrence's pay to the level of Bale's. But we are now in a position to see how our arguments also impugn the second rectificatory strategy, according to which we should decrease Bale's pay to the level of Lawrence's. We can concede that this strategy conduces to the achievement of fairness by eliminating a morally arbitrary inequality. But if the No Intrinsic Value Claim is correct - and we have offered two independent arguments for this verdict - then this fairness is not of any intrinsic value.

Of course, if the money withheld from Bale were donated to a poverty relief organisation, then decreasing Bale's pay would be commendable. But this does not vindicate the Fairness Argument, for the Fairness Argument recommends decreasing Bale's pay in order to address Lawrence's fairness complaint, not in order to benefit the world's poor. Similarly, we might commend decreasing Bale's pay on the grounds that

\footnotetext{
${ }^{14}$ For a similar case, see Casal (2007: 307).
} 
it reduces the degree to which his holdings exceed his just share. But, again, this observation does not salvage the Fairness Argument.

In case some readers are sceptical of the No Intrinsic Value Claim, it's worth noting that the considerations adduced in our presentation of the Excess Objection ground an additional argument against the second rectificatory strategy. As we have accepted throughout, Lawrence suffers some unfairness. She is paid less than Bale, and her lower pay appears to be attributable to a morally arbitrary factor. But as we have also emphasised, Lawrence's holdings are unjust. These holdings comprise resources that Lawrence is morally required to relinquish. Now, the second rectificatory strategy recommends eliminating the unfairness between Lawrence and Bale by reducing Bale's pay to the level of Lawrence's. One problem here is that, in doing so, it also appears to offer a normative endorsement of Lawrence's pay. It states that we should maintain Lawrence's pay, and that other millionaires such as Bale ought to be remunerated at the same level. But Lawrence's pay is unjust. These observations reveal that the second rectificatory strategy is vitiated by a narrowness of vision. It focuses myopically on the morally irrelevant micro-unfairness between Lawrence and Bale, while ignoring larger problems. As a result of this tunnel vision, it ends up sanctioning injustice.

Our conclusion, then, is that the Fairness Argument for rectifying millionaire inequality is unsuccessful. In the next section, we examine an alternative case for rectifying millionaire inequality.

\section{The Discrimination Argument}

In this section, we set aside considerations of fairness and instead examine the claim that female victims of millionaire inequality suffer from a form of wrongful discrimination. At the outset, it bears noting that discrimination raises concerns that 
are distinct from those that we considered above. This is because an individual can be a victim of discrimination even when she is denied goods that would constitute unjust holdings or to which she is otherwise not entitled. To see this, consider the case of a job applicant who is unqualified for the job to which she applies, but whom is denied an interview not on these grounds, but because she is black. Clearly, the applicant is the victim of wrongful discrimination, even though she is not entitled to the job in question. This insight is important since we might draw parallel conclusions in cases of millionaire inequality, namely that Lawrence and other female millionaires paid less than their male counterparts are victims of wrongful discrimination, despite the fact that they are not entitled to the higher income that they are denied. This is the Discrimination Argument.

\subsection{Discrimination and Market Demand}

What makes discrimination wrong? According to one view, discrimination can be wrong in virtue of the discriminator's bad intentions (Alexander 1992; Slavny and Parr 2015). The strongest intuitive support for this judgement is provided by reflection on cases like the one described above, where an unqualified applicant is denied a job on explicitly prejudiced grounds. ${ }^{15}$ Here, the character of the employer's intention is sufficient to render her decision wrongfully discriminatory, and thus we need not appeal to any other considerations in order to deliver the conclusion that the applicant is a victim of a serious injustice. We can call this the Intention-Based Discrimination Argument.

\footnotetext{
${ }^{15}$ In fact, even critics of the relevance of intentions to permissibility recognise the force of such cases. See Scanlon (2008: 69-70).
} 
We suspect that some cases of millionaire inequality involve discrimination of this kind, which is performed by employers acting on explicitly sexist motives (and recent charges brought against certain Hollywood producers has strengthened this suspicion). Under these circumstances, it's straightforward to establish wrongful discrimination and we should condemn the treatment on this basis. However, in other cases, those who determine the salaries of female millionaires might not be motivated by explicit prejudice, such as sexist beliefs, and may instead be responding to variations in the level of market demand for the talents of male and female stars. One possibility is that, when differences in earnings between victims and beneficiaries of millionaire inequality are generated in this way, there is no wrongful discrimination. We can call this the Market Demand Reply to the Intention-Based Discrimination Argument.

Two considerations support this reply. ${ }^{16}$ First, even if the contributions of male and female millionaires seem relevantly identical at first blush, closer examination may reveal subtle differences between them. For example, male tennis players typically exhibit higher levels of strength, stamina, and speed than their female counterparts. Thus, there can be variations in the goods that the relevant employees produce. Second, even when this is not the case, differences may still emerge simply in virtue of variations in others' reactions to apparently identical goods. For example, it may be that audiences tend to prefer watching male news presenters to equally talented female ones. The point is not that male news presenters are typically more talented than female news presenters, in any technical sense of that claim. It's possible that both sets of presenters

\footnotetext{
${ }^{16}$ These two grounds parallel the distinction between technical qualifications and reaction qualifications. See Wertheimer (1983).
} 
perform identically well, but that audiences still happen to respond more positively to male news presenters than female ones.

In practice, it's often difficult to discern which of these factors affects market demand in a given case, since this task is an epistemically complex one and the line between the two factors is blurred, even at the conceptual level. As Iris Marion Young notes, market evaluations of qualifications and contributions of individuals are greatly influenced by societal values, such as whether they incorporate norm-following behaviour, social competencies, and conform to role expectations (e.g. expectations toward women that differ from those toward men). Because of this, it's practically difficult to separate variations in goods from variations in reactions (Young 2011: ch. 7). ${ }^{17}$

The difficulty of determining the exact basis of market demand is important for two reasons. First, it casts doubt on the claim that those who determine millionaires' salaries must be motivated by explicit prejudice, including sexist beliefs (which is not to deny that they sometimes are). According to the Market Demand Reply, some millionaire inequalities are better understood as tracking differences in the goods produced by different celebrities and/or variations in consumer reactions to those goods. Second, it may be possible to appeal to these considerations in order to defend some millionaire inequalities. According to this defence, it's justifiable to pay female celebrities less than their male counterparts when and because this reflects the lower level of market demand for their services. This is the view of the tennis player, Novak Djokovic, who has claimed that tennis players' salaries should reflect 'who attracts more attention, spectators and who sells more tickets' (BBC News 2016).

\footnotetext{
${ }^{17}$ See also Gheaus (forthcoming) for further discussion of the ways in implicit biases shape the opportunities and evaluations of women.
} 
The Market Demand Reply appeals to the suggestion that, when determining Lawrence's pay, some employers may be responding to the level of market demand for her talents, rather than acting on bad intentions. What should we make of the Market Demand Reply? A first response invokes the fact that political philosophers disagree about whether and why differences in the level of market demand for employees' services can justify inequalities in pay. For example, proponents of some forms of radical egalitarianism believe that the fact that an individual's services are in high demand never justifies paying her more than someone whose service are in low demand (Cohen 2008). Those drawn to this view will be unpersuaded by the Market Demand Reply, believing that the misfortune of lacking talents that are in greater demand is as morally arbitrary as gender and race, and so allowing salaries to depend on this factor is as wrongfully discriminatory as allowing salaries to depend on these other attributes. However, since this rejection of market mechanisms is controversial, and because the relevant considerations have been explored at length elsewhere, we shall set it aside.

A second response holds that the Market Demand Reply merely passes the buck. More specifically, it suggests that even if employers are not wrongfully discriminating against female victims of millionaire inequality, perhaps consumers are doing so. According to this line of argument, consumers act on wrongfully discriminatory preferences that generate an incentive for employers to offer lower pay to female actors than to their male co-stars. By focusing on consumers' preferences, we can uphold the verdict that Lawrence is a victim of intention-based wrongful discrimination without laying the blame at the door of an employer, who may simply be responding to market demand.

In order to sustain this response, it's necessary to do more than show that consumers' preferences generate an incentive for producers to offer lower salaries to Lawrence and other female celebrities. In particular, proponents of this reply must show that 
consumers are motivated by explicit prejudice, or have a similarly morally defective kind of intention. (From the perspective of the Intention-Based Discrimination Argument, if consumers' intentions are entirely innocent, then there can be nothing more objectionable about the inequality in income between Lawrence and Bale than the inequality in income between a highly talented actor and a weak actor.) However, this task is not straightforward, since the judgements that inform consumers' preferences regarding female actors can be very different from the obviously morally defective intentions of an employer who rejects an applicant on explicitly racist grounds. Certainly, consumers with a stronger preference for seeing Bale than Lawrence need not exhibit the kind of animus and explicit prejudice that motivates the employer in the case with which we began and that are necessary to classify the employer's act as intentionally malicious.

In the light of these facts, we conclude that the Intention-Based Discrimination Argument is likely to fail. But we cannot infer from this that we must reject the

Discrimination Argument tout court. This is because employers and/or consumers may be engaged in forms of wrongful discrimination against female millionaires that do not rely on the nature of their intentions. In the remainder of this section, we explore these possibilities in greater detail.

\subsection{Reconsidering the Market Demand Reply}

One problem with the Market Demand Reply is that it adopts an uncritical attitude towards consumer preferences and the inequalities that these preferences generate. In particular, it fails to recognise that, irrespective of whether these preferences are explicitly prejudiced in themselves, they may have been generated under unjust or 
otherwise problematic circumstances, and this may make a difference to our moral evaluation of the inequalities that emerge from them.

For example, unjust gender-related social norms play a significant role in shaping our preferences and expectations about goods and services (Haslanger 2015). Social norms determine which roles men and women are expected to fulfil, often to the disadvantage of the latter (Haslanger 1993; Young 2011: 193-197). This is important because, irrespective of whether consumers' preferences are themselves explicitly sexist, they are often shaped by an unjust culture of sexism.

Do these considerations show that Lawrence and other female millionaires are victims of wrongful discrimination? One way in which those who answer 'yes' might support this judgement is by appealing to the fact that the sexist injustice that characterises our world harms Lawrence, in the sense that it renders her worse off economically than she would otherwise be. In a world free from sexist injustice, Lawrence's earnings would be greater than at present, more closely equalling the income of Bale. This is because, in the absence of sexist injustice, social norms would not pervasively shape consumers' preferences in a way that creates an incentive for producers to offer lower pay to Lawrence than to her male co-stars. We can call this the Harm-Based Discrimination Argument. $^{18}$

Three features of this argument warrant emphasis. First, despite some similarities - for example, both are concerned with the distribution of income - the Harm-Based Discrimination Argument and the Fairness Argument make rather different claims. The Harm-Based Discrimination Argument relies on a counterfactual claim about how

\footnotetext{
${ }^{18}$ For discussion of the idea that discrimination can be wrong when and because it's harmful, see LippertRasmussen (2013).
} 
Lawrence would have fared economically under alternative conditions, and, in particular, about how she would have fared in a world without sexist injustice (Goff 2016). By contrast, the Fairness Argument invokes an interpersonal claim about how Lawrence fares economically in comparison with other individuals, and, in particular, about how she fares in comparison with her male co-stars.

Second, the success of the Harm-Based Discrimination Argument does not depend on the controversial premise that consumers act wrongly when expressing a stronger preference for Bale over Lawrence, or for Djokovic over Williams. The argument appeals to the more modest claim that consumers' preferences may be shaped by sexist background injustice and that we should be sensitive to the harmful effects that this may have on people's earnings. It's consistent with this latter claim that consumers' preferences, though shaped by unjust social norms, are not themselves unjust.

Third, the Harm-Based Discrimination Argument's core claim is that female millionaires are wronged because they fare less well economically than they would if consumers' preferences were not shaped by sexist social norms. In order to make sense of this idea, we do not need to commit to any particular account of what makes a social norm sexist. It could be because of these norms' propensity to undermine equality of opportunity; it could be because of what they express; or it could be something else. We do not need to take a stand on this tricky issue. We take this to be an attractive feature of Harm-Based Discrimination Argument since it means that we can combine it with a range of different answers to that question.

However, the Harm-Based Discrimination Argument is vulnerable to an objection, which stems from the fact that, though Lawrence is economically worse off than she would have been in a world without sexist injustice, it's not obvious that this is the 
relevant counterfactual baseline against which to make the comparison. An alternative option is to accept what we call the Comprehensive Baseline Claim. This claim holds that the relevant comparison for the purposes of the Harm-Based Discrimination Argument is with how an individual would have fared in a world without any economic injustice, sexist or otherwise. This claim takes seriously the fact that, while Lawrence can complain that sexist norms shape consumers' preferences in a way that renders her less well off economically than she would have been in the absence of these unjust norms, there are other economic injustices from which Lawrence benefits. In determining whether Lawrence is harmed in the relevant sense, we should compare Lawrence's current economic situation with how she would have fared in a world that lacks not only the sexist component of economic injustice, but economic injustice more generally. ${ }^{19}$ Since Lawrence is not worse off economically than she would have been in the absence of all economic injustice, those who endorse the Comprehensive Baseline Claim must deny that she is a victim of wrongful discrimination, according to the Harm-Based Discrimination Argument.

In support of this objection, let's return to the earlier example of Slaves, in which the government of a slave state distributes slaves on a random basis, with the result that some citizens end up owning more slaves than others. Now, let's also suppose that the ruling government came to power through an unjust coup d'état, and that the pre-coup government distributed slaves more equally. Can a citizen who receives no slaves appeal to the Harm-Based Discrimination Argument, citing the fact that she is worse

\footnotetext{
${ }^{19}$ Or rather, we should apply this comparison to the occupants of the generic role 'elite female actor'. If the world had diverged from its actual historical trajectory in the radical way that we are envisioning, it is hard to imagine that the same people would fill the same roles (or that subset of roles that exists in both worlds).
} 
off now than she would have been had the unjust coup not occurred? Intuitively, the answer is 'no', and our analysis helps to make sense of why this is the case. The slaveless citizen cannot complain in this way because the pre-coup state of affairs is the wrong counterfactual baseline against which to make the comparison. As the Comprehensive Baseline Claim states, the slaveless citizen must compare her situation to how she would have fared had the unjust coup not occurred and had the pre-coup government not been a slave state. Along similar lines, Lawrence and other female millionaires cannot appeal to the fact that they would have earned more in a world without distributive gender injustice to support the judgement that they are victims of wrongful discrimination. They cannot appeal to this fact because they are much better off economically than they would be in a world that satisfies not only the requirements of distributive gender justice, but also those of distributive justice more generally.

At this point, one might press an objection against the Comprehensive Baseline Claim. We can illustrate this objection by considering a case in which a female millionaire is a victim of sexual harassment. It might be said that such harassment need not render this millionaire worse off, all-things-considered, than she would be in a fully just world in which she is not sexually harassed, but in which she also earns much less than she does at present, and that the Comprehensive Baseline Claim therefore prevents us from saying that she is harmed. Given that this conclusion is unacceptable, the Comprehensive Baseline Claim must be rejected.

In reply, this objection misunderstands our claim. Our claim is that in order to identify the specific kinds of economic harm that concern us, the relevant counterfactual world with which to draw comparisons is one that lacks any kind of specifically economic injustice. If in that counterfactual world one fares less well economically than one does in our world, then one is not harmed economically. This claim has no implications for 
the kind of counterfactual scenario that is appropriate when attempting to identify other, non-economic, forms of harm. Thus, we can readily accept that the envisaged millionaire is harmed by the sexual harassment she suffers, even if she would be less well off economically in a fully just world.

The upshot of these considerations is that we should reject the above attempt to salvage the Harm-Based Discrimination Argument, and thus that we are not entitled to appeal to this argument in order to sustain the conclusion that Lawrence and other female millionaires are victims of wrongful discrimination.

\subsection{Discrimination and Disrespect}

So far, we have focused exclusively on individuals' economic entitlements. But this approach is too narrow, since it overlooks the way in which inequalities can express an insulting message about the comparative moral worth of the victims and beneficiaries, and how the expression of such a message can be disrespectful. This idea is a powerfully intuitive one. It helps to explain what is so morally abhorrent about laws that require black passengers to sit at the back of the bus, or policies that offer payments to minorities to emigrate (Hellman 2011; Gerver 2018; Anderson and Pildes 2000). Failing to recognise the symbolic significance of these policies is failing to recognise the nature of the injustice that the victims suffer. It might be argued that we can sustain similar judgements in the cases with which we are concerned. This is the DisrespectBased Discrimination Argument.

This argument rests on the claim that paying female celebrities less than their male counterparts expresses an insulting message about their comparative moral worth, and perhaps also about the comparative moral worth of men and women more generally, 
and that we should object to millionaire inequalities on this basis. ${ }^{20}$ Importantly, this argument is not concerned with what an agent intends his acts to express. Rather, it's concerned with how his acts can reasonably be interpreted. If an act can reasonably be interpreted as insulting, performing that act can be disrespectful, regardless of whether the insult is intended. These considerations allow us to condemn conduct as wrongfully discriminatory on the basis of the message it sends, without having to inspect the intentions of those acting.

One advantage of the Disrespect-Based Discrimination Argument is that it furnishes us with a response to the Market Demand Reply. To see how it does this, let's consider a US Supreme Court case from 1964, in which an Alabaman restaurant, Ollie's Barbeque, refused to open its doors to black customers following the enactment of the Civil Rights Act on the grounds that, if it were required to do so, the restaurant 'would lose a substantial amount of business' (Katzenbach v. McClung 1964: 297). ${ }^{21}$ The injustice of the owner's conduct can be fully explicated only if reference is made to the insulting message that it conveyed. Intentionally or otherwise, the owner's act sends a clear symbolic message, namely that black and white customers are not moral equals. Given the social context in which it's performed, and how it could reasonably be expected to be perceived in light of this context, the owner's act is deeply disrespectful. In 1964 Alabama, black citizens were routinely treated as moral inferiors and had been subject to unequal and unjust treatment for centuries. Part of this unjust treatment

\footnotetext{
${ }^{20}$ Gheaus reaches the same conclusion (forthcoming). Part of the distinctive contribution of our paper is to reinforce this conviction, by exploring the nature of this disrespect-based wrong, especially in the light of the Market Demand Reply.

${ }^{21}$ We have simplified our presentation of this complex legal case so as to focus on the aspect that is most relevant to assessing the plausibility of the Market Demand Reply.
} 
consisted precisely in segregation and in refusing black citizens entry to various establishments. Refusing to admit black customers is disrespectful, regardless of the owner's intentions, in virtue of this unjust social background, and the role it plays in determining how the action is reasonably interpreted. In other words, refusing admission is disrespectful because it's expressively in line with the enforcement of racial hierarchy and segregation (Anderson and Pildes 2000: 1528).

Moreover, the fact that the owner was (allegedly) acting only to maximise profits does little to mitigate the disrespectfulness of their act. The judgement that they have acted disrespectfully is grounded in their failure to be adequately responsive to the social context in which they were acting, and to the social meaning that this context would inevitably lend to their conduct. A crucial implication of these observations is that the Market Demand Reply is insufficient to stave off assertions of wrongful discrimination when the conduct in question expresses an insulting message, as it does in this case.

Importantly, it seems plausible to hold that these considerations transfer over to the case of millionaire inequality. Even if unequal remuneration really does reflect variations in the level of market demand for celebrities' talents, such remuneration plausibly remains wrongfully discriminatory given the insulting message that it's likely to convey regarding the comparative moral worth of men and women (Gheaus forthcoming). Contemporary liberal societies, including Britain and the US, do not treat women in a manner that is comparable to the manner in which 1960s Alabama treated African Americans. Nevertheless, these societies have deeply sexist histories. In the recent past, these societies have upheld practices that deprived women of vitally important goods (such as the right to vote and to own property) and that failed to protect women from serious harms (such as marital rape). Moreover, these societies continue to be marked by deep gender inequalities. Women suffer from a variety of serious 
inequities, including a disproportionate burden of household labour, high levels of domestic violence, negative stereotyping, and socio-political marginalization (Satz 2010: 144-146). Given this social context, it's reasonable to regard unequal remuneration as insulting, whatever its actual source. Employers who pay women less than men often fail to be adequately responsive to the social context in which they are acting, and to the meaning that their acts can reasonably be expected to convey in light of that context. This is a failure of respect.

In drawing the parallels that we have drawn, we do not mean to claim that the symbolic content in cases of millionaire inequality is as unambiguously disrespectful as it is in paradigmatic examples of racial injustice. In the example of Ollie's Barbeque, the restaurant claims to be acting on market demand shaped by explicit prejudice on the part of its patrons. However, in cases of millionaire inequality, we grant that employers may be providing unequal remuneration on the basis of consumer demand that is not motivated by explicit prejudice. Some critics of our analysis might argue that this difference renders cases of millionaire inequality invulnerable to the Disrespect-Based Discrimination Argument. We disagree. What matters is that, in both cases, the acts with which we are concerned are widely and reasonably understood (particularly amongst the victims) to express a disrespectful message about the comparative moral worth of different individuals.

These issues are part of a larger picture regarding the systematic oppression of members of a socially salient group (Young 2011: ch. 7). Our observations emphasise that cases of millionaire inequality occur within the context of a world in which women of all backgrounds are systematically disadvantaged relative to men, and perhaps it's these facts that make Lawrence's complaints so serious. 


\section{Extending Our Arguments?}

We started this article by noting that cases of millionaire inequality elicit conflicting intuitions. Whereas the unequal remuneration involved looks like a troubling case of gender injustice, it's natural to feel uneasy when confronted with the suggestion that multimillionaires are somehow being paid inadequately, given their fortunes. Crucially, however, these celebrities are not the only class of people who have more wealth than that to which they are entitled. Many people who are less wealthy than millionaires but who are nevertheless well-off plausibly also have more than their just share. Indeed, it is not completely implausible to think that this is true of even the average citizen of a rich society, including (we suspect) many readers of this paper. This should prompt us to reflect on the extent to which our conclusions generalise beyond society's very highest earners to those who are only moderately well-off. We do not deny that our conclusions can be generalised, but, in this final section, we shall note some obstacles to doing so.

Let's begin with the Fairness Argument, which we argued provides no compelling basis on which to rectify millionaire inequalities. This is because, according to the Just Holdings Condition, improving the fairness of a distribution is intrinsically valuable only when the distribuenda are justly held, which is not true of individuals who earn vastly more than that to which they are entitled.

At first glance, we might expect fairness-based arguments in the context of those who are moderately well-off to be defeated by the same kinds of considerations that defeat those arguments in the context of the super-rich. But on reflection, this is a little too quick. To see why, note that there are two senses in which celebrities such as Lawrence can be said to earn more than that to which they are entitled. First, they lack a justified 
claim to their earnings because their enormous wealth entails a huge missed opportunity to alleviate the severe disadvantages of the world's poorest. Because each millionaire has so much, there is a lot that they can do for those who have little. Second, when millionaires are unfairly paid less than their counterparts, the material benefits they forgo are extravagant luxuries. ${ }^{22}$

Moreover, it is plausible that, if these millionaires were to relinquish their excess wealth, this would free up sufficient resources to eliminate severe poverty. In other words, were they to give up their luxuries, contenting themselves instead with the level of wealth held by the moderately advantaged, extreme deprivation might cease to exist.

In contrast to the wealth that is unjustly held by the super-rich, the wealth that is held by any moderately well-off individual need not represent an excessively large forgone opportunity to assist the world's poor. Furthermore, if those who are extremely wealthy were to relinquish their opulence, the wealth held by the moderately advantaged might be unnecessary to alleviate severe poverty. Finally, the benefits foregone by moderately well-off victims of unfairness need not be trivial. If an average citizen of an affluent country is treated unfairly at work, for example, and thereby earns a smaller income than some of her colleagues, the benefits that she forgoes can be significant. From the perspective of alleviating global poverty, then, the reasons for which the wealth of millionaires is unjustly held do not translate straightforwardly to the wealth of the moderately-advantaged.

\footnotetext{
${ }^{22}$ More extremely, we might even conceptualize these resources as 'surplus money', meaning that we should give wealth above a certain level zero moral weight in comparison with urgent claims to those funds. For example, see Robeyns (2017). For related discussion, see Frank (2010: ch. 5).
} 
In Section 2.2, we noted (but did not explore) several additional reasons for why the wealth of millionaires may be unjustly held, besides the fact that it represents a failed opportunity to rectify severe disadvantage. For example, we noted that egalitarians might invoke the unfairness of the vastly superior prospects enjoyed by the wealthy compared to others, the pernicious effects that great economic inequalities have on social relations, enabling some to have power over and dominate others, and the detrimental effects such inequalities tend to have on political procedures. Further investigation is needed in order to determine whether any of these additional reasons render the wealth of the moderately advantaged unjustly held as well.

What should we say about the various Discrimination Arguments that we considered in Section 3? Do our conclusions about these arguments generalise beyond society's very highest earners? Again, there are some reasons to think not. In the first instance, it bears emphasizing that the causes of the gender pay gap throughout most of the income distribution may differ from the causes of Hollywood's gender pay gap, which we have supposed is partly to do with differences in market demand. For the overwhelming majority of women, their lower earnings is nothing to do with this factor. Rather, studies suggest that it is often a product of the gendered division of labour and, more specifically, the fact that, since most mothers have primary responsibility for childcare, they must find forms of employment that are compatible with the demands of family life. ${ }^{23}$

\footnotetext{
${ }^{23}$ For discussion, see Kleven et. al (2019). Of course, other factors, such as number of years in education and corporate culture, may exert an influence as well, even at the upper end of the income distribution. For discussion, see Burkhauser et. al (Working Paper) and Keller, Molina, and Olney (Working Paper).
} 
What is more, some studies suggest that, even when considerations of market demand do not arise, the causes of the gender pay gap among the super-rich differ from the causes of the gender pay gap throughout most of the income distribution. ${ }^{24}$ That is to say that, as a general matter, the barriers facing society's highest earning women whether in Hollywood or elsewhere - likely differ from those facing most other women in the labour market. If this is the case, then there is a clear reason to treat cases of millionaire inequality as a distinctive phenomenon, such that we should avoid extending our arguments further down the income distribution.

To conclude, we would like to emphasise a final point. Irrespective of the extent to which our conclusions in this paper generalise beyond Hollywood, we believe that there are a host of further reasons to object to society's gender pay gap, many of which take issue with the deeply unjust gendered social norms that profoundly affect our lives. ${ }^{25}$ None of our arguments count against the existence of such reasons or, indeed, imply that they are less forceful than commonly assumed. After all, to deny that there is anything intrinsically valuable, say, about a fair distribution of income between moderately well-off men and women would not be to say that there are no weighty reasons to overturn the social norms that sustain the existing pattern of economic inequality between them.

\footnotetext{
${ }^{24}$ This claim is supported by the fact that various government policies, such as parental leave schemes, that improve most women's employment opportunities have no effect on, and may even be detrimental to, the prospects of society's highest-earning women. See Corekcioglu, Francesconi, and Kunze (Working Paper).

${ }^{25}$ For examples of such objections, see Gheaus (2012), Okin (1989), Schouten (2019), Watson and Hartley (2018), and Williams (2000).
} 


\section{Acknowledgements}

We are grateful to the British Academy for the Small Research Grant (ref: SG162565) that supported this research. For helpful feedback on presentations of earlier versions of this paper, we thank audiences at Aarhus University, the Central European University, and at the 2018 WPSA Annual Meeting in San Francisco. We also thank the participants in a workshop on the theme of this paper that took place at the University of Essex, with special thanks going to our discussant, Anne Phillips. For discussions or written feedback on this paper, we thank an anonymous reviewer for this journal, Richard Arneson, Paul Bou-Habib, Mollie Gerver, Anca Gheaus, Sarah Goff, Gur Hirschberg, Mirjam Müller, Andrew Williams, Annette Zimmermann, and students on the MSc in Political Theory at the LSE. Our greatest debt is to Clare Burgum.

\section{References}

Alexander, L. 1992. What Makes Wrongful Discrimination Wrong? Biases, Preferences, Stereotypes, and Proxies. University of Pennsylvania Law Review 141: 149219.

Anderson, E. and Pildes, R. 2000. Expressive Theories of Law: A General Restatement. University of Pennsylvania Law Review 148: 1503-1575.

BBC News. 2016. Novak Djokovic Questions Equal Prize Money in Tennis. BBC News, $21^{\text {st }}$ March 2016, URL: http://www.bbc.co.uk/news/world-us-canada-35859791.

Burkhauser, R., Hérault, N., Jenkins, S., and Wilkins, R. Working Paper. What Accounts of the Rising Share of Women in the Top 1\%. NBER Working Paper 27397.

Caney, S. 2009. Cosmopolitanism and Justice. In Contemporary Debates in Political Philosophy, ed. T. Christiano and J. Christman, 387-407. Malden: Blackwell.

Casal, P. 2007. Why Sufficiency Is Not Enough. Ethics 117: 296-326.

Christiano, T. 2012. Money in Politics. In The Oxford Handbook of Political Philosophy, ed. David Estlund, 241-257. Oxford: Oxford University Press. 
Cohen, G.A. 2008. Rescuing Justice and Equality. Cambridge: Harvard University Press.

Corekcioglu, G., Francesconi, M., and Kunze, A. Working Paper. Do Generous Parental Leave Policies Help Top Female Earners? CESifo Working Paper 8330.

Estlund, D. 2008. Democratic Authority: A Philosophical Framework. Princeton: Princeton University Press.

Frank, R. 2010. Luxury Fever: Weighing the Cost of Excess. Princeton: Princeton University Press.

Fraser, N. 2013. How Feminism Became Capitalism's Handmaiden - and How To Reclaim It. The Guardian, 14 ${ }^{\text {th }}$ October, 2013, URL: https://www.theguardian.com/commentisfree/2013/oct/14/feminism-capitalisthandmaiden-neoliberal.

Gerver, M. 2018. Paying Minorities to Leave. Politics, Philosophy, \& Economics 17: 3-22.

Gheaus, A. 2012. Gender Justice. Journal of Ethics \& Social Philosophy 6: 1-24.

Gheaus, A. Forthcoming. The Feminist Argument against Supporting Care. Journal of Practical Ethics.

Gheaus, A. Unpublished Manuscript. Fair Equality of Opportunity in Unjust Circumstances.

Goff, S. 2016. How to Trade Fairly in an Unjust Society: The Problem of Gender Discrimination in the Labor Market'. Social Theory and Practice 42: 555-580.

Grierson, J. 2017. Who Earns What Among BBC's Top Talent. The Guardian, $19^{\text {th }}$ July 2017, URL: https://www.theguardian.com/media/2017/jul/19/who-earns-whatamong-bbcs-top-talent.

Haslanger, S. 1993. On Being Objective and Being Objectified. In A Mind of One's Own: Feminist Essays on Reason and Objectivity, ed. L.M. Anthony and C.E. Witt, 209-252. Oxford: Westview.

Haslanger, S. 2015. Resisting Reality: Social Construction and Social Critique. Oxford: Oxford University Press.

Hellman, D. 2011. When Is Discrimination Wrong? Cambridge: Harvard University Press.

Hug, L., Sharrow, D. and You, D. 2017. Levels and Trends in Child Mortality. New York: United Nations Children's Fund.

Human Development Report 2016. 2016. Human Development for Everyone. New York: United Nations Development Programme.

Katzenbach v. McClung. 1964. 379 U.S. 294.

Keller, W., Molina, T., and Olney, W. Working Paper. The Gender Gap Among Top Business Executives. NBER Working Paper 28216. 
Kleven, H., Landais, C., Posch, J., Steinhauer, A., and Zweimüller, J. 2019. Child Penalties across Countries: Evidence and Explanations. American Economic Review: Papers and Proceedings 109: 122-126.

Lawrence, J. 2015. Why Do I Make Less Than My Male Co-Stars? Lenny Letter, $14^{\text {th }}$ October 2015, URL: http://www.lennyletter.com/work/a147/jennifer-lawrencewhy-do-i-make-less-than-my-male-costars.

Lippert-Rasmussen, K. 2013. Born Free and Equal: A Philosophical Inquiry in the Nature of Discrimination. Oxford: Oxford University Press.

Okin, S.M. 1989. Justice, Gender, and the Family. New York: Basic Books.

Raz, J. 1986. The Morality of Freedom. Oxford: Oxford University Press.

Robeyns, I. 2017. Having Too Much. In NOMOS LVI: Wealth. Yearbook of the American Society for Political and Legal Philosophy, ed. J. Knight and M. Schwartzberg, 1-44. New York: New York University Press.

Satz, D. 2010. Why Some Things Should not be for Sale: The Moral Limits of Markets. New York: Oxford University Press.

Scanlon, T.M. 2002. The Diversity of Objections to Inequality. In The Ideal of Equality, ed. M. Clayton and A. Williams, 41-59. Basingstoke: Palgrave.

Scanlon, T.M. 2008. Moral Dimensions: Permissibility, Meaning, Blame. Cambridge: Harvard University Press.

Schemmel, C. 2011. Why Egalitarians Should Care About Distributions. Social Theory \& Practice 37: 365-390.

Schouten, G. 2019. Liberalism, Neutrality, and the Gendered Division of Labor. Oxford: Oxford University Press.

Singer, P. 2009. The Life You Can Save: Acting Now to End World Poverty. London: Picador.

Slavny, A. and Parr, T. 2015. Harmless Discrimination. Legal Theory 21: 100-114.

The Telegraph. 2017. Female BBC Stars' Letter to Tony Hall Demanding Equal Pay in Full. The Telegraph, 22 ${ }^{\text {nd }}$ July 2017, URL: http://www.telegraph.co.uk/news/2017/07/22/female-bbc-stars-letter-demandingequal-pay-tony-hall-full.

Watson, L. and Hartley, C. 2018. Equal Citizenship and Public Reason: A Feminist Political Liberalism. Oxford: Oxford University Press.

Wertheimer, A. 1983. Jobs, Qualifications, and Preferences. Ethics 94: 99-112.

Williams, J. 2000. Unbending Gender: Why Family and Work Conflict and What To Do About It. Oxford: Oxford University Press.

Williams, S. 2017. How Black Women Can Close the Pay Gap. Fortune, $31^{\text {st }}$ July 2017, URL: http://fortune.com/2017/07/31/serena-williams-black-women-equal-pay. 
Young, I.M. 2011. Justice and the Politics of Difference. Princeton: Princeton University Press. 